\title{
Skill, drive and luck: the discovery and development of heparin
}

A s the CMAJ celebrates its centenary it is worth remembering that another fixture of the medical landscape will also soon turn 100. Heparin, one of the oldest drugs still in clinical use, remains ubiquitous in medical care today. As the first safe and effective anticoagulant, heparin was transformative. Pulmonary embolism, previously a feared killer, became treatable. Two celebrated medical technologies, renal dialysis and the heart-lung machine, owe their existence to heparin, as neither would be possible without anticoagulation. Heparin and its derivatives also continue to play a key role in the management of venous thromboembolic disease and myocardial infarction.

The story of heparin begins with William Henry Howell. Born in Baltimore, Maryland he pursued undergraduate and graduate studies at the newly formed Johns Hopkins University. There he became interested in coagulation, which had intrigued physicians for centuries but was poorly understood at the time. This was well demonstrated by his supervisor's suggestion that Howell investigate the difference in coagulability between arterial and venous blood. ${ }^{1}$ Howell quickly realized the futility of this project and went on to devise his own research. After receiving his $\mathrm{PhD}$ in 1884 , he joined the newly opened Johns Hopkins School of Medicine as a professor of physiology, where he edited An American Text-Book of Physiology.

This textbook would prove crucial to the discovery of heparin as it would lead Jay McLean to seek out Howell's laboratory at Johns Hopkins. ${ }^{2}$ McLean's life to that point had been difficult. His father died when he was a boy, leaving McLean responsible for funding his own education. During a

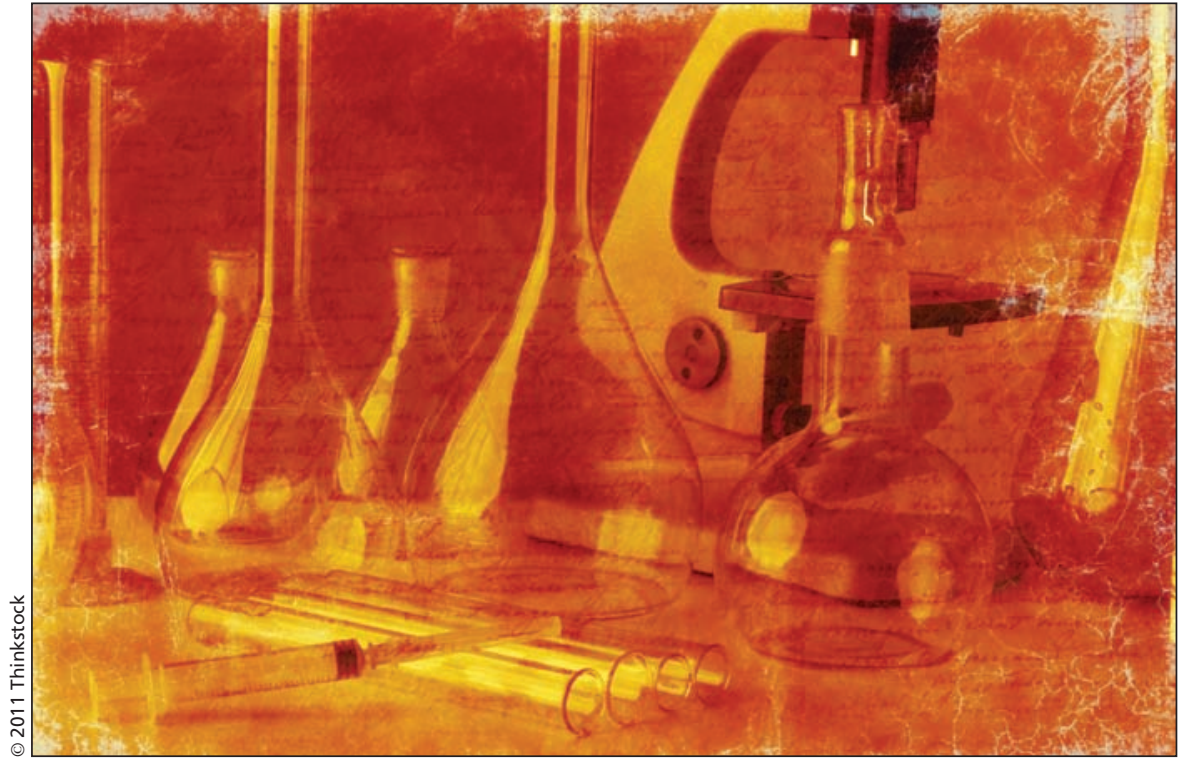

year working odd jobs in order to finance his third year of premedical studies at the University of California at Berkeley, McLean discovered Howell's textbook and became fascinated with the research possibilities it offered. After completing his undergraduate studies he was intent on a career in surgery, and sought admission to the rigorous medical school at Johns Hopkins. Initially denied entry, he saved money for 15 months and made the transcontinental move to Baltimore anyway. This proved to be a fortunate decision, as upon his arrival he learned of an unexpected vacancy at the medical school and was accepted.

McLean was convinced that physiology research was essential for him to become a successful academic surgeon. He approached Howell, requesting a project that he could complete quickly, as he only had sufficient funds for one year of school. Howell suggested that McLean demonstrate the procoagulent properties of cephalin. McLean finished this work early, and went on to isolate other phosphatides from his samples. His original intent was to show that the removal of cephalin would reduce the procoagulent activity of these samples. To his surprise, however, he found that two of his samples actually had anticoagulant properties., ${ }^{2,3} \mathrm{He}$ informed Howell of his discovery, but it is unclear how seriously either took it at the time. McLean published a paper in 1916 detailing his work on cephalin, but only briefly mentioned the prospect of an anticoagulant. ${ }^{4}$ Although McLean would later return to Howell's laboratory, he abandoned his search for an anticoagulant, as he felt a procoagulant would be more valuable for the ongoing war effort.

Howell and another medical student, L. Emmett Holt, continued work to isolate a potential anticoagulant compound. Howell at first appeared to acknowledge McLean's role, including attributing discovery of an anticoagulant to him in his Harvey Lecture in 1917. ${ }^{4}$ In 1918, Howell and Holt published an account of an anticoagulant 
isolated from liver which, because of its origin, they gave the name heparin. Though possibly chemically distinct from the compound isolated by McLean, it clearly derived from his work. In subsequent papers, Howell detailed improved extraction protocols for heparin and identified its chemical properties. These did not cite McLean's earlier paper, however.

For many years Howell would be identified as the sole discoverer of heparin. McLean, apparently out of respect to his former supervisor, refused to contest this state of affairs while Howell was still living. After Howell's death in 1945, however, McLean began an extensive and ultimately successful campaign to draw attention to his critical role in the discovery. ${ }^{4}$ Although it is unlikely that we will ever know the priority of the contribution of these two scientists, it is clear that both played important roles in the identification and laboratory preparation of heparin.

Howell and McLean's early work made great strides in characterizing heparin in vitro, but problems with the purity and activity of the compound would prevent clinical use for more than a decade. Howell reported using heparin to facilitate blood transfusions in human subjects in 1928, but found that some participants developed febrile reactions and chills. ${ }^{1}$ Much of the true translation of heparin into clinical practice occurred in Toronto under the oversight of Charles Herbert Best, already famous for his role in discovering insulin. Best had identified the usefulness of an anticoagulant both clinically and for in vitro experiments during doctoral studies in England. Upon returning to a professorship at the University of Toronto in 1929, he assembled a team with two objectives. Arthur Charles and David Scott at the university's Connaught Laboratories focused on removing the toxic side effects by improving heparin's purity while Best and coworkers worked to confirm heparin's anticoagulant properties.

Charles and Scott published a series of papers on methods to improve the preparation of heparin. One innovation, autolysis of the liver tissue, greatly increased yield, but produced such powerful odors that later work had to be relocated from the laboratories on campus to a farm owned by Connaught Laboratories. ${ }^{5}$ Charles and Scott next turned their attention to crystallizing heparin to increase its purity, but encountered considerable difficulty. Around this time, Clarence Crafoord, a Swedish cardiovascular surgeon who would later perform the first surgical repair of aortic coarctation, approached the Swedish scientist Erik Jorpes about isolating heparin for clinical use. Jorpes visited the Best team and learned about their work on both insulin and heparin. ${ }^{5} \mathrm{He}$ then returned to Sweden and began his own work on purifying heparin. Ultimately the two teams would maintain a cordial but competitive relationship, with each making contributions to the purification and clinical use of heparin.

As pure, nontoxic heparin became available, the Canadian researchers turned their attention toward clinical studies. These were carried out by Best, Gordon Murray, Louis Jacques and T.S. Perrett. They first reported results in experimentally injured canine veins, where they found that administering heparin allowed healing of the vessel without thrombus formation or toxicity. They soon began work in humans, where they identified the absence of toxicity for purified heparin and demonstrated its effects on coagulation time. They published the first account of their results in the CMAJ in $1936 .{ }^{6}$ They later went on to describe heparin's use in humans as prophylaxis against thrombosis during surgery and in other clinical situations.

Heparin would go on to shape the careers of several team members. Gordon Murray immediately recognized the potential for heparin and used it when developing both pioneering surgeries and the first dialysis system in North America. Jacques went on to become a world authority on heparin and published over 450 articles on the subject. Best, who had always identified himself more with insulin than with heparin, stopped working on heparin with the onset of World War II, but did play a significant role in publicizing Jay McLean's contribution to its discovery.
The story of heparin's discovery and development is a testament to the importance of basic science research and the sometimes unexpected medical applications that result. It is also a story of dogged determination and luck. Despite involving some of the most significant figures in medicine, the discovery itself may have been by a medical student. Heparin is also a distinctly Canadian discovery, with much of the most important work of translating it from the laboratory to the bedside occurring in Toronto. Almost 100 years later, research continues into heparin and its derivatives, as is aptly demonstrated by the most recent Canadian Institutes of Health Research/CMAJ Award for the novel use of low-molecular-weight heparin in venous thromboembolism. ${ }^{7}$ This is something worth celebrating.

\section{Richard Norman BSc, MASc \\ Class of 2014 \\ Faculty of Medicine \\ University of Toronto \\ Toronto, Ont.}

This essay was one of two winning entries in the "To Essayer" contest for medical students, interns and residents, commemorating 100 Years of Medical Knowledge at CMAJ. Our judging panel included Dr. Diane Kelsall, Deputy Editor, $C M A J$; Dr. Paul Potter, History of Medicine, University of Western Ontario; Dr. Dorian Deshauer, Associate Editor, CMAJ; Sagar Dugani $C M A J$ Editorial Board member and class of 2012 in the MD/PhD program at the University of Toronto; and Barbara Sibbald, Deputy Editor. Thank you to all those who entered the contest, and congratulations to the winners.

\section{References}

1. Fye WB. Heparin: the contributions of William Henry Howell. Circulation 1984;69:1198-203.

2. McLean J. The discovery of heparin. Circulation 1959; $19: 75-8$

3. Marcum JA. The origin of the dispute over the discovery of heparin. J Hist Med Allied Sci 2000;55:37-66.

4. McLean J. The thromboplastic action of cephalin. Am J Physiol 1916;41:250.

5. Marcum JA. The development of heparin in Toronto. J Hist Med Allied Sci 1997;52:310-37.

6. Murray DW, Jaques LB, Perrett TS, et al. Heparin and vascular occlusion. Can Med Assoc J 1936;35: 621-2.

7. Hull R. Essay for the CIHR/CMAJ award: The role of low-molecular-weight heparin therapy venous thromboembolism. CMAJ 2011;183:E344-6.

CMAJ 2011. DOI:10.1503/cmaj.111795 